\title{
BILDESERIE
}

\section{NYE, GAMLE SAUDI-ARABIA}

Saudi-Arabia er et land med lang his- Hele tiden har det vært et uttalt mål å torie, som samtidig har gått igjennom bevare det distinkte saudiske, både voldsomme endringer i løpet av få tiår. for myndigheter og blant innbyggere. Få steder er dette mer synlig enn i I denne bildeserien vil vi gå forbi overhovedstaden Riyadh. Byen ligger like skriftene og vise forskjellige sider av ved området hvor den første saudiske Saudi-Arabia gjennom bilder fra staten hadde sitt utspring på 1700- hovedstaden.

tallet. Siden 2017 har en rekke sosialt liberaliserende reformer også satt sitt BILDER: CHARLOTTE LYSA preg på byen, blant annet gjennom underholdningsarrangementer. 


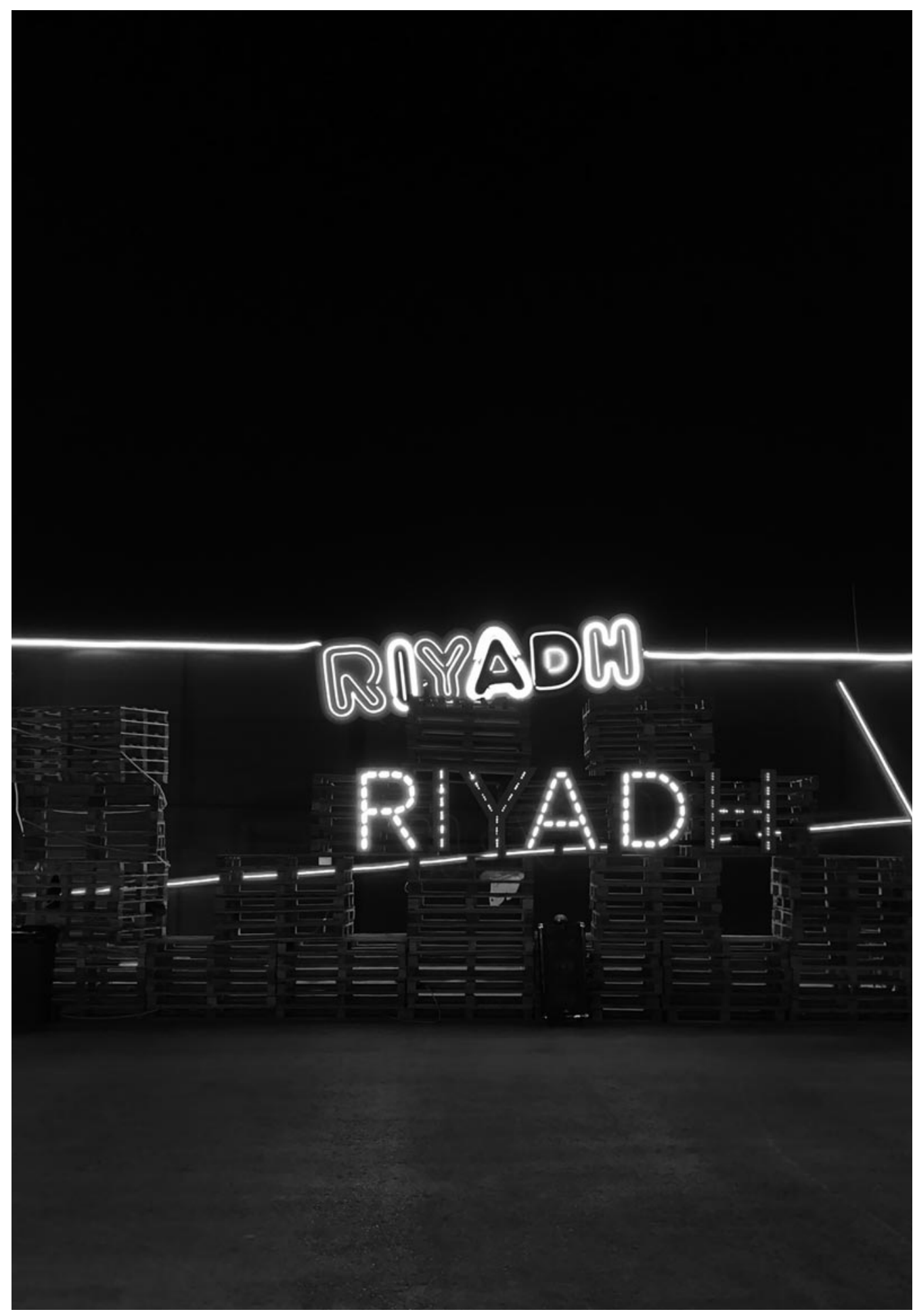




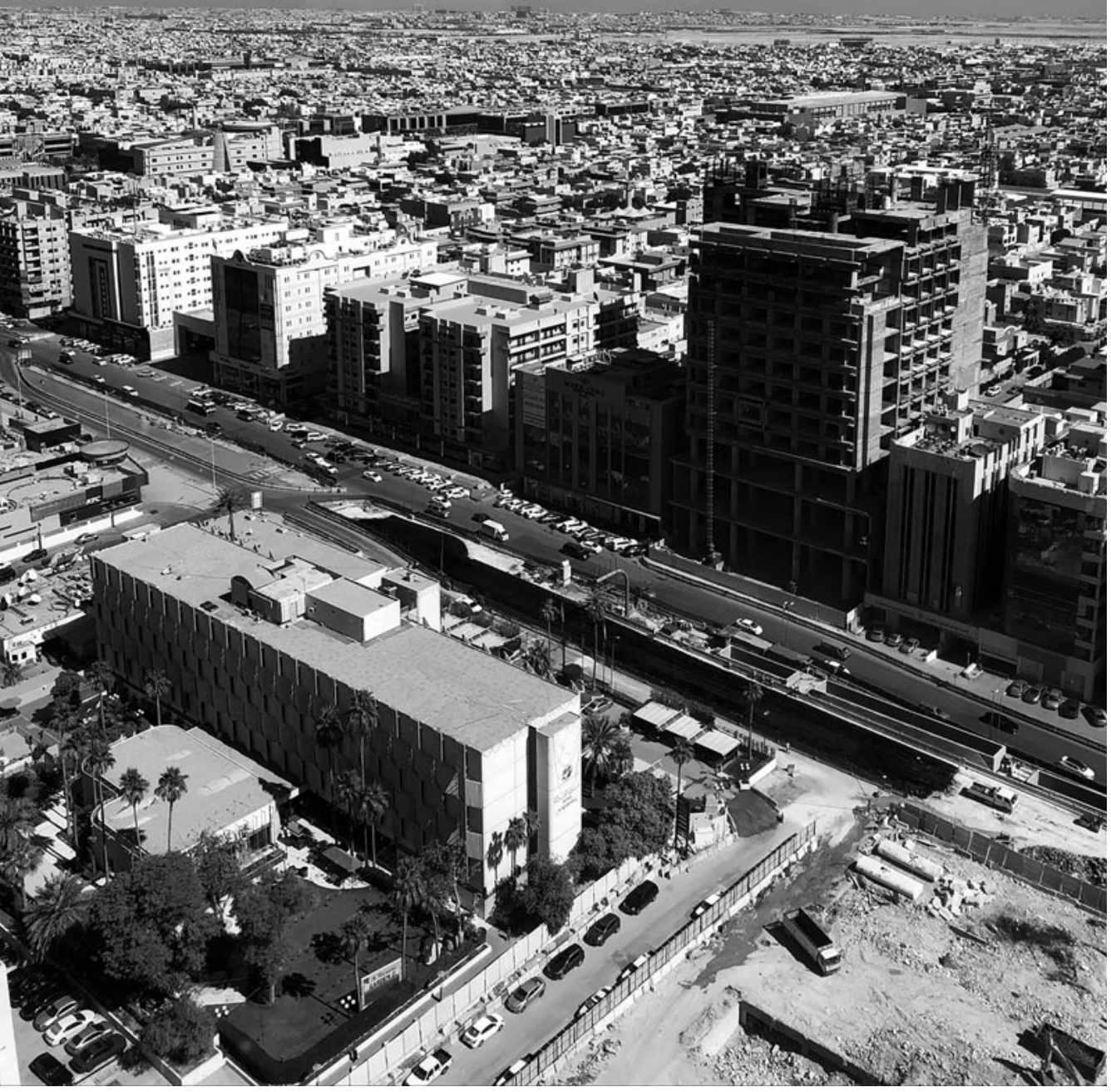




$$
\text { }
$$




\section{J}

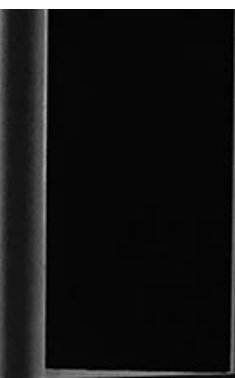

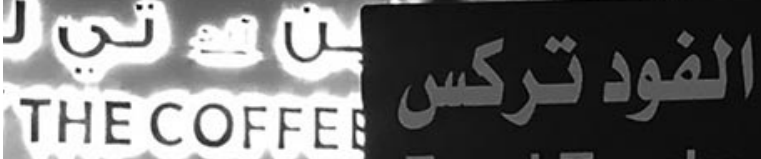

Food Trucks
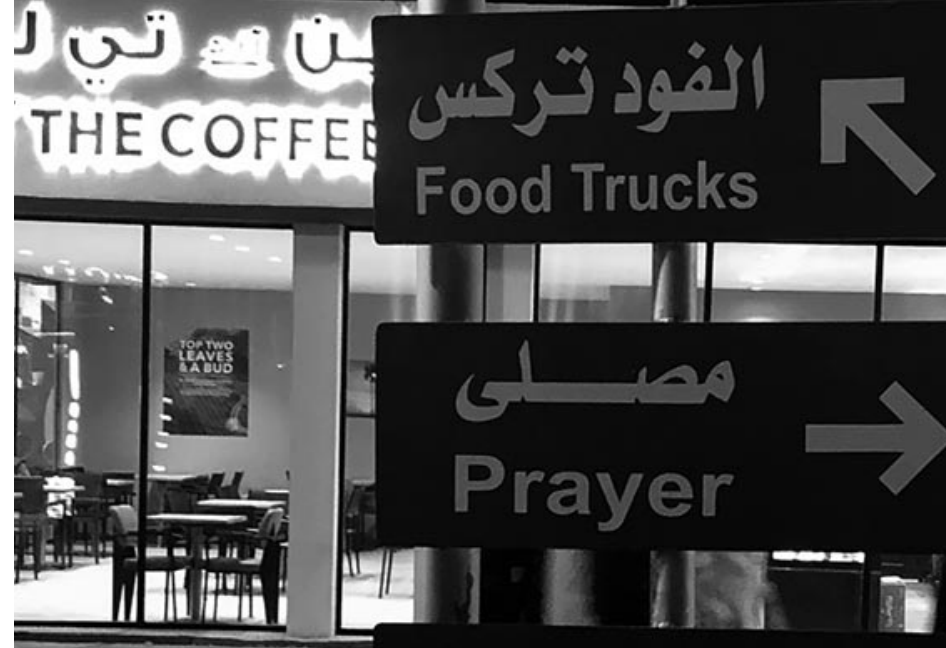

Prayer

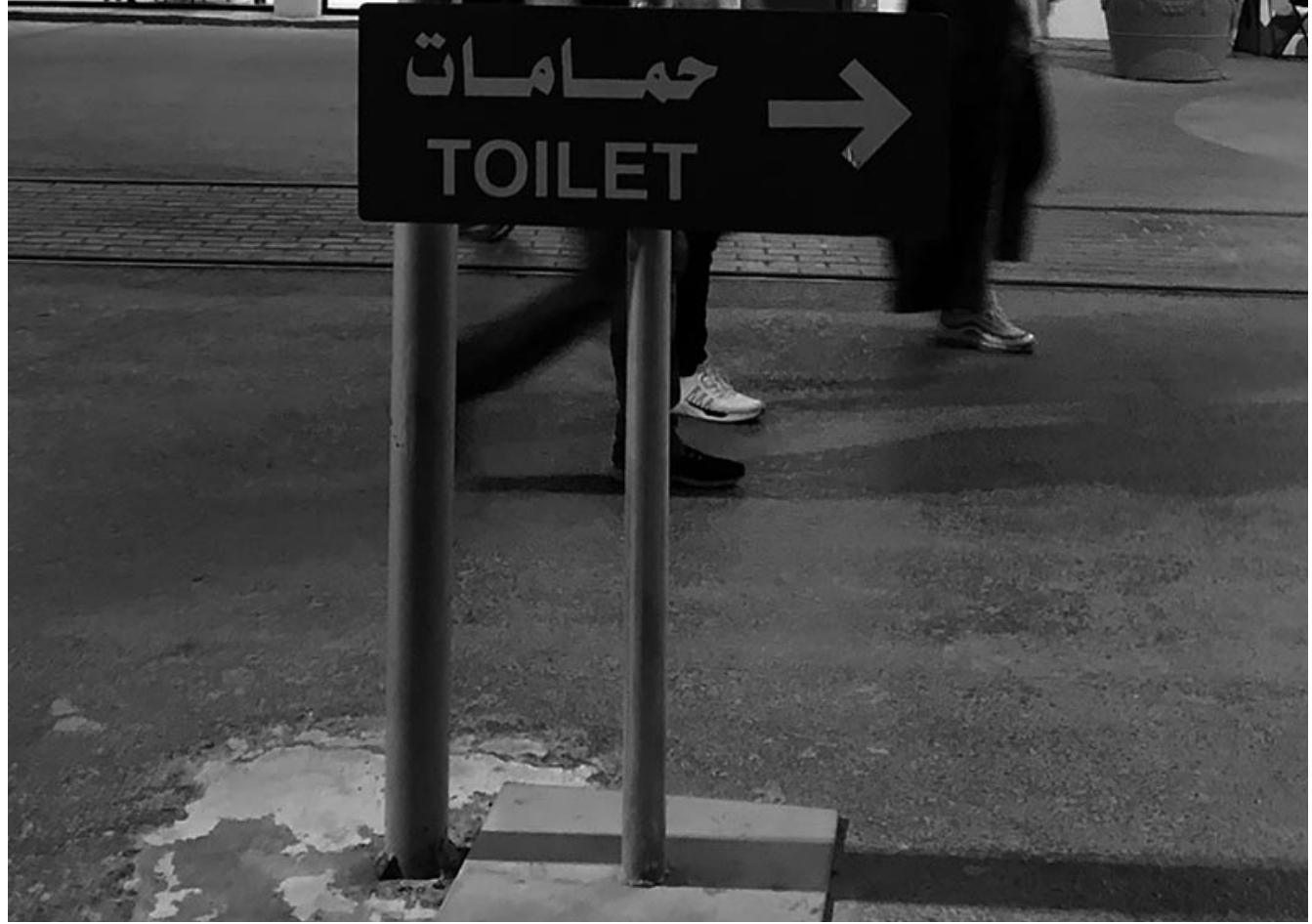




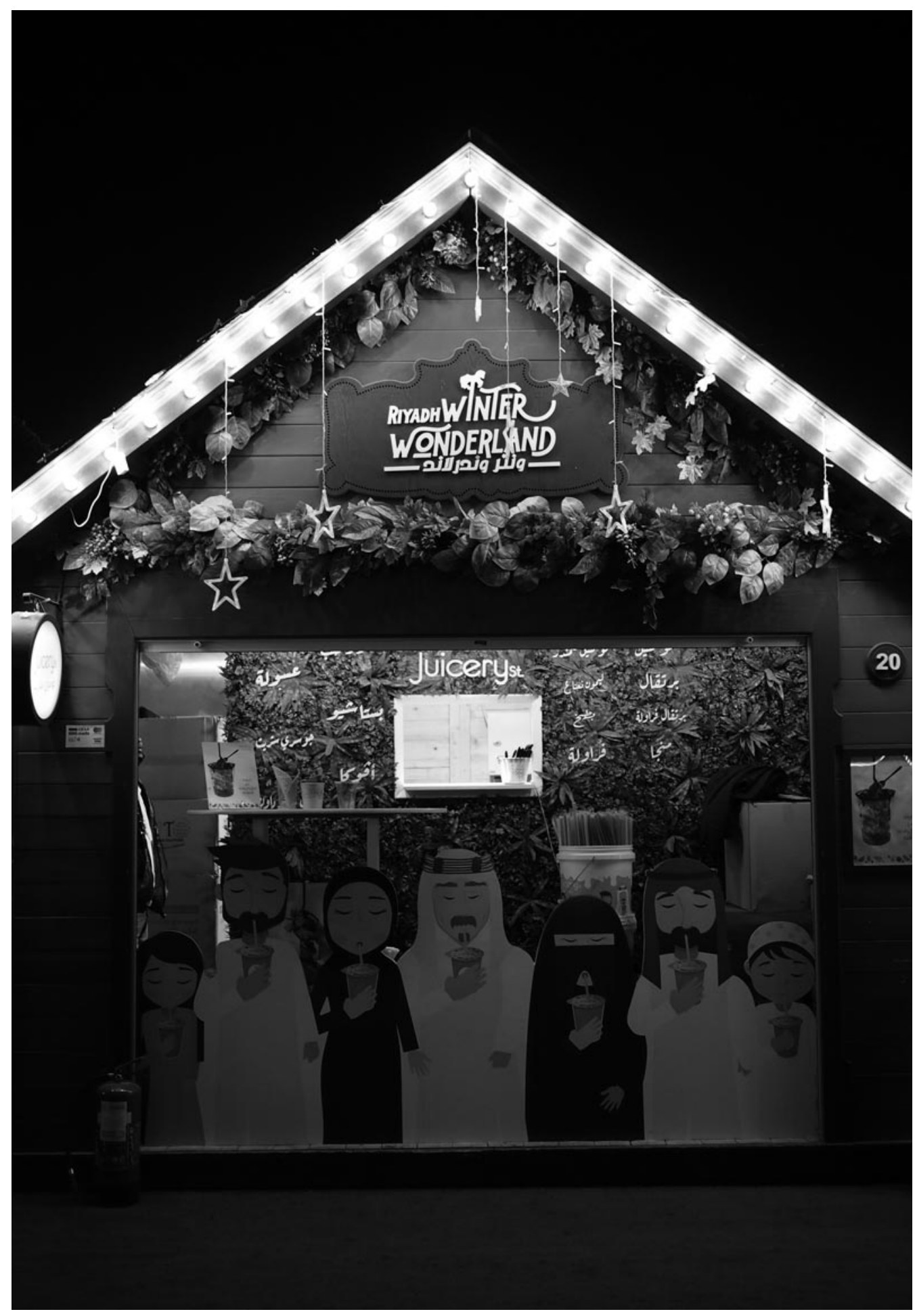




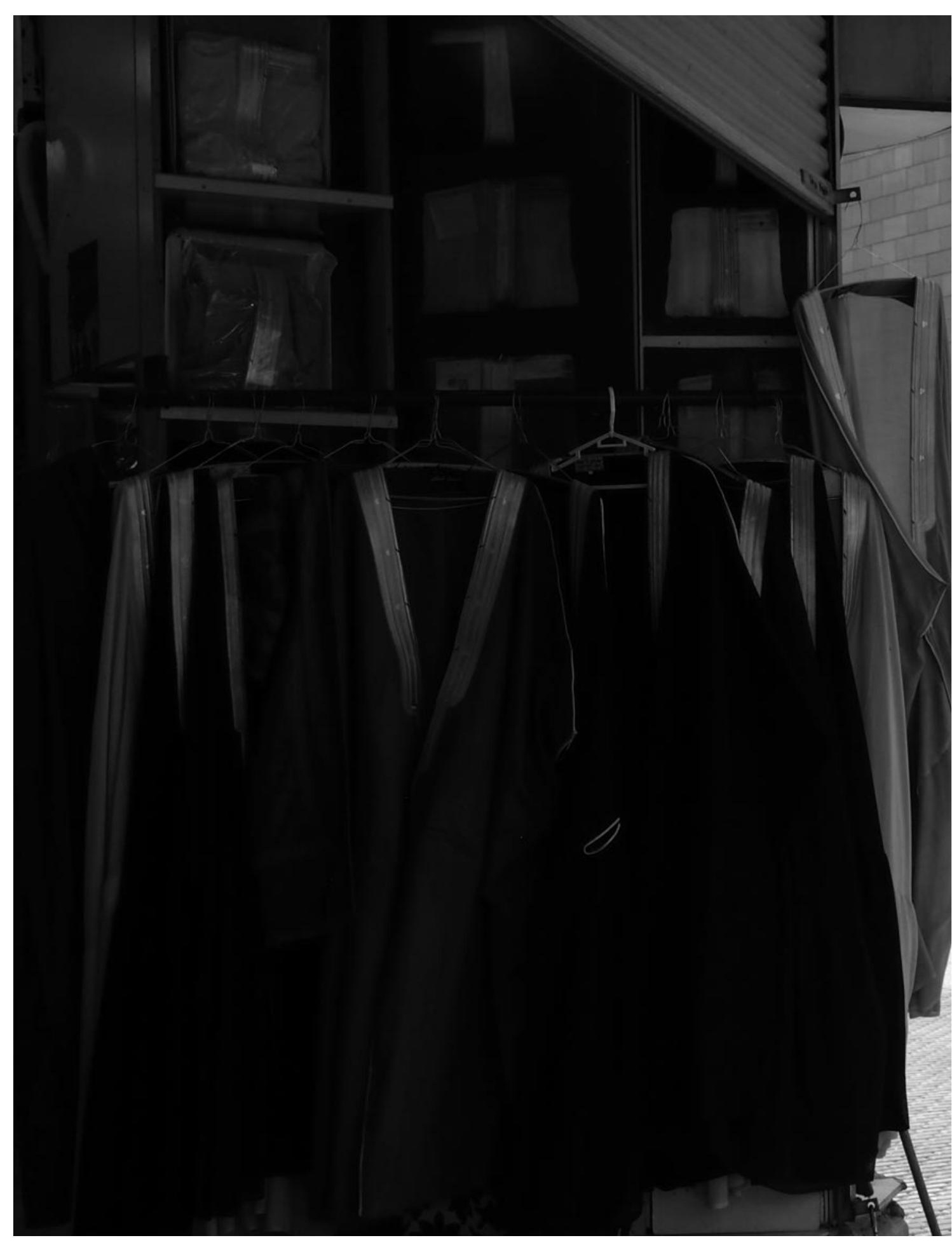





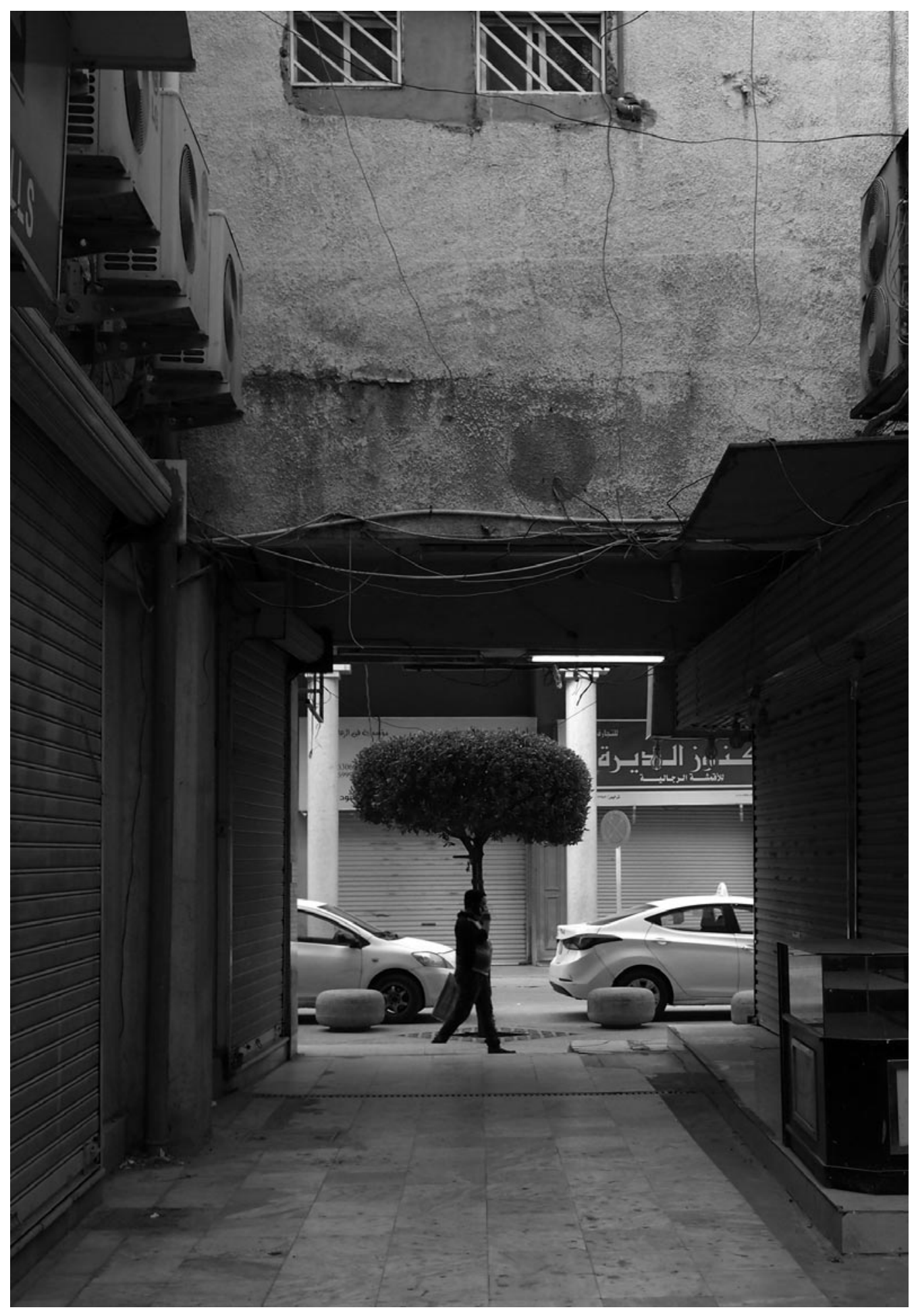




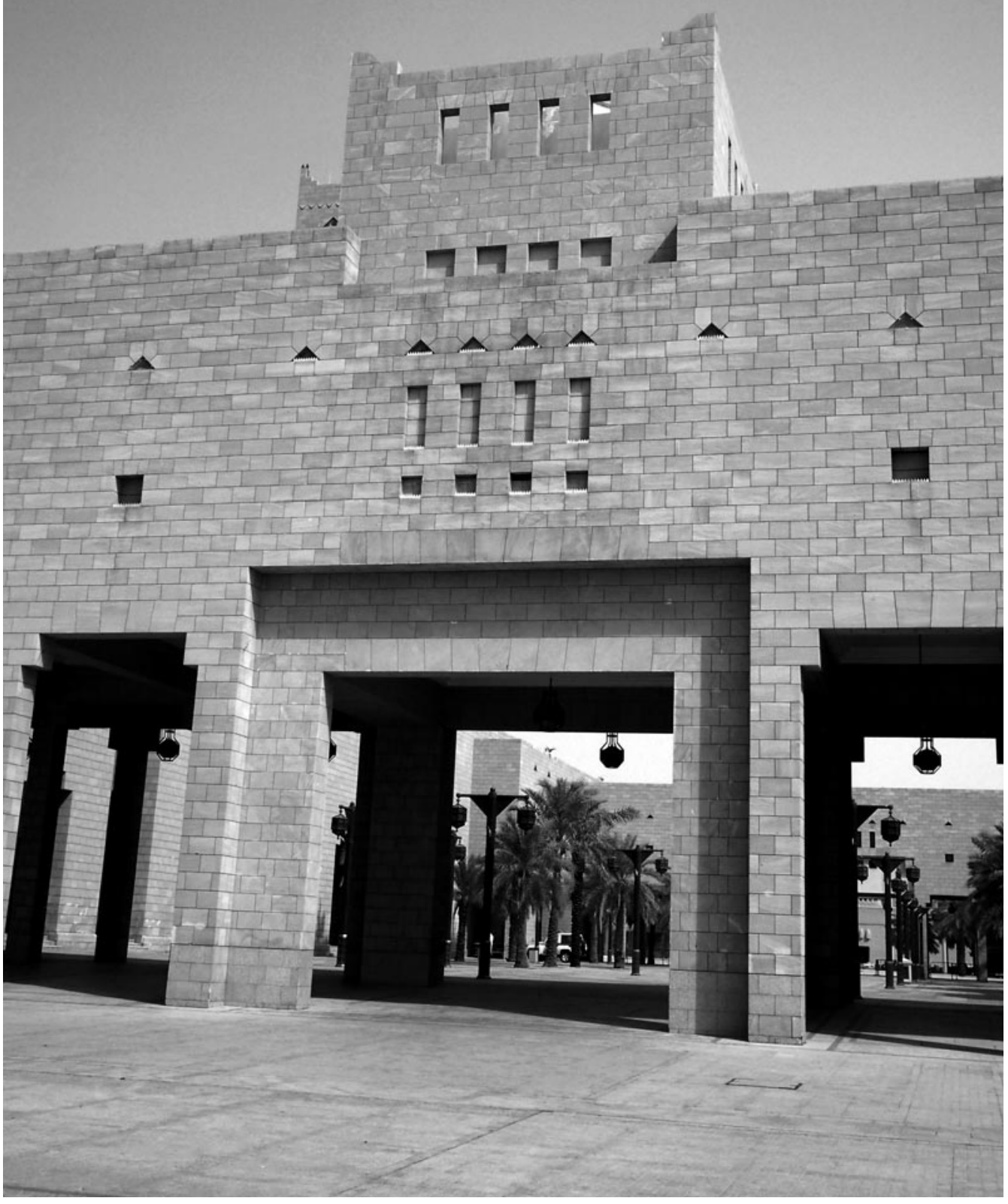




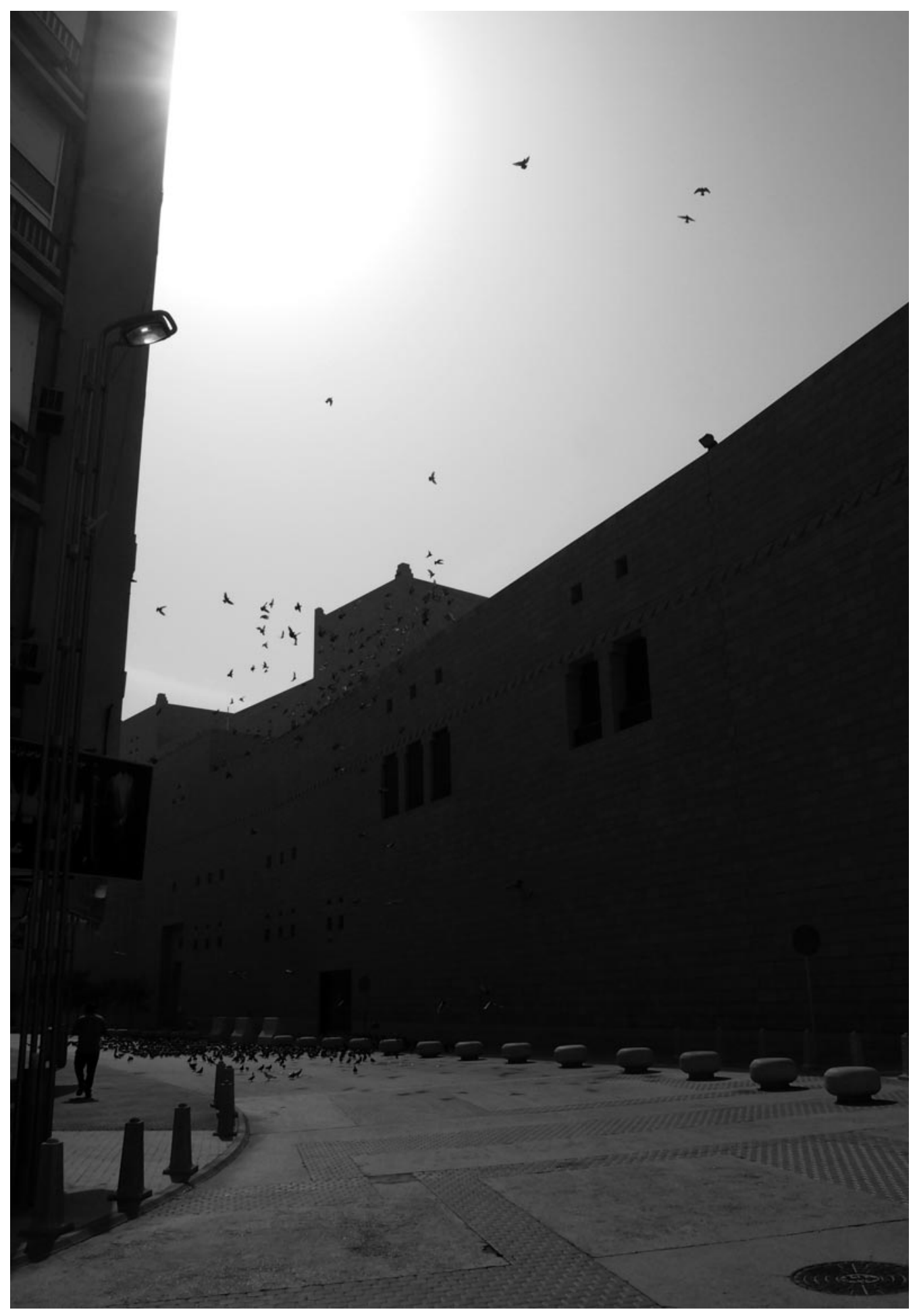

